\title{
Rethinking Shelter and Tiny House Communities: Dignity Village, Portland and Lessons for San Luis Obispo
}

\author{
Anne Wyatt \\ MCRP Cal Poly (2005) \\ Former County of San Luis Obispo Planning Commissioner
}

\begin{abstract}
Homelessness is a growing concern for communities in the United States, and planners are looking for innovative ways to respond to it. Anne Wyatt, a planner in the San Luis Obispo area and an egress from Cal Poly's MCRP program, discusses Dignity Village, a city-recognized encampment of 60 families in Portland. She points out both benefits and challenges, and takes away several inspiring lessons for planning.
\end{abstract}

D gnity Village Portland (DV), a community of approximately 50 tiny houses with a common house with kitchen, toilets and showers, provides a successful operating model of how we may collaboratively shelter a small segment of the approximately 2,300 unhoused persons in San Luis Obispo. The non-profit Hope's Village of San Luis Obispo now attempts to acquire a ten-acre parcel for a similar village. History and lessons from Portland may strengthen chances of success for Hope's Village.

In 2012, when I visited Dignity Village, it had housed approximately 60 persons at a time over a ten-year period. Lease renewals with the City of Portland were underway to extend the dollara-year lease and continue the community operation.

"People call this a homeless camp, but we have homes. We are no longer homeless. Why is it a homeless camp then?"

David, Dignity Village resident

David, our tour guide, posed this pertinent question at the start of our Dignity Village tour. He ushered my friend Elaine and me around on a typical gray Portland day that threatened rain. David immediately pointed out one of many challenging realities: there are different ideas how to describe and define "homeless" persons, before we even begin to address sheltering them. Becky Jorgeson, a San Luis Obispo advocate for unhoused persons and president and founder of Hope's Village, suggests substituting the terms "unhoused" or "landless" for "homeless," (personal communication June 14, 2014). Spellcheck does not accept "unhoused," but I have

Note about the author: Anne Wyatt is a freelance writer specializing in housing and housing policy. She enjoys wandering around peeking into open windows observing the relationships between houses and their people, challenging assumption, restoring funky old buildings and working with materials at hand. She is completing her first book, Downward Mobility: Revisiting Shelter, a kooky travel story. A former County of San Luis Obispo Planning Commissioner, she graduated from Cal Poly with an MCRP in 2005. Contact her at a.reneewyatt@gmail.com. adopted this term. Labels affect the way we frame things, so they are useful to call out and consider at the start of a journey.

Elaine and I-housers working toward provision of shelter for all-had come to Portland's Dignity Village armed with Patagonia rain clothes to learn more about how this unconventional community worked. We recognized that issues are complex. Still, averting our eyes neither makes homelessness nor messy challenges go away.

\section{General Description and History}

DV resembled my sister's suburban-gated community in some respects, fenced in with one official way in and out. Similar to entering at my sister's enclave north of San Francisco, Elaine and I signed in at the security hut, as required, and stated our purpose of entry, lacking a contact. As two women in sporty clothes hopping out of a Honda Fit, we were deemed worthy of entry and welcomed, even though at the time we knew no residents and lacked official business.

Figure 1: Sign and mail box at Dignity Village's entrance. (photo by the author)

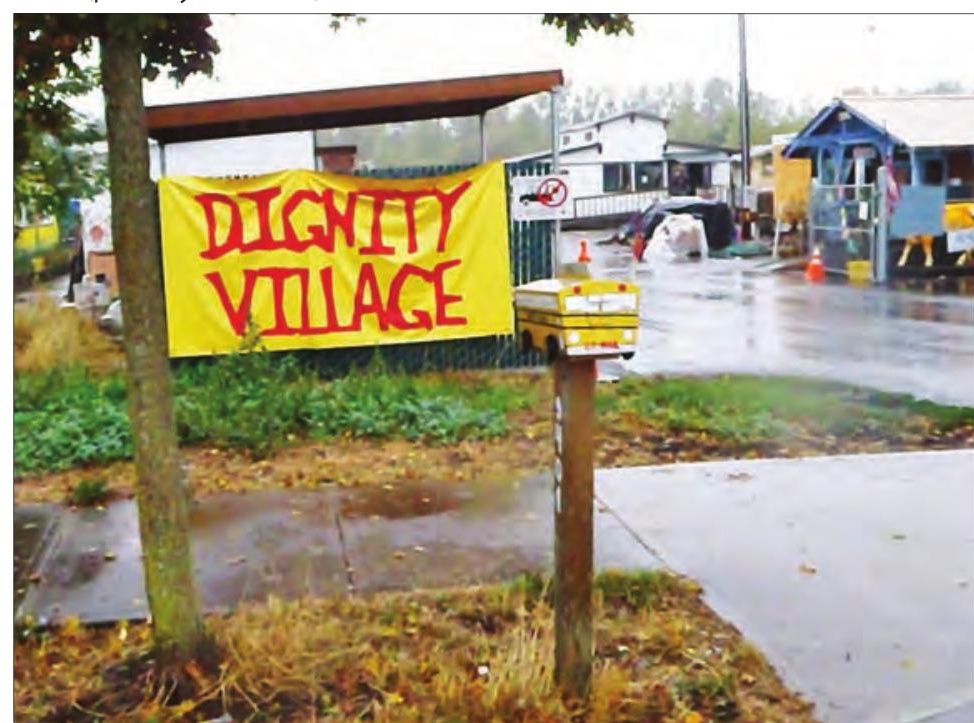


Suburban-gated community comparisons may end at the front security gate. Some would say comparison to the jail next door to DV would be more apt. A municipal composting facility on the other side of DV made it challenging to hear David, our guide. Large grinding equipment has a way of disrupting things, as do jets. Beyond DV and the noisy composting facility was PDX, Portland's airport. The site, amongst public facilities, was city-owned and available, not pristine.

Established in 2000, DV arose out of a self-organized "Out of the Doorways" movement. A group of unhoused persons bonded together and demanded a better solution than sleeping in doorways. The goal, according to founding documents provided by community organizer Mark Lakeman (2004), was "to create a community oriented, efficient, sustainable, temporary residential living community for homeless adult residents."

The original intent, according to Lakeman, was to serve County residents not already served by existing services. Residency was not limited to this target population, but this group included those excluded from other programs, including parolees, 288 and 290 sexual offenders, and persons with no state issued identification.

Inclusivity, serving of the underserved, makes theoretical sense. There is long standing tradition of attempt at equal treatment. Jesus just broke bread and passed the wine without asking a lot of questions, as the story gets told. However, some residents complained to me on the visit that the inclusionary vision made day-to-day living problematic. I recently heard a similar complaint in an Occupy Detroit squatter settlement. The Occupy Movement may have crumbled under the weight of its noble, inclusive ideals. DV, like so many groups I have watched and participated in, struggled as it attempted to align ideals with day-to-day reality.

As planners, we talk high-mindedly about diversity and inclusivity, but practical challenges involved are important considerations; inclusivity is a nice theoretical concept, but it is hard to live, build, and create when crazy, scary thieves and druggies live next door, howl at the moon at all hours, and steal your bike, bread, wine, and tools. Many planners live in tidy condo complexes and subdivisions with homeowners' associations, with locked garage doors, and thick booklets of covenants, conditions, and restrictions for reasons. Diversity can be like Mother Theresa or that admired relative we often choose not to stand too close to because she makes us look selfish, petty, and forces us out of our comfort zones as we challenge assumptions and decide whether we want to live with the stench of reality or not.

DV was a two-acre cluster of approximately 50 self-built 200 square foot or smaller "temporary movable" structures (think toolsheds). The City of Portland leased the property, about the amount of space that ten typical suburban homes would sit on, to the not-for-profit 501(c)(3) community group in 2000. In addition to the common house, kitchen, toilets, and showers, the community shared raised-bed gardens, a computer room, garden shed, parking area, sales (recycle) area, and entry station.

Over the years, DV has housed 50-70 adults at one time, under $1 \%$ of the estimated Portland unhoused population. The other 99\% of unhoused persons in Portland were not pounding on DV doors demanding admittance. Given this context, it is important to acknowledge that DV is one option for housing unhoused persons, not a one-size-fits-all solution.

While not a solution for all, the DV has proven transformational for some. Mark Lakeman, a Portland architect who helped found DV, inspired a large group and kicked off the community village movement in San Luis Obispo during a talk he gave in 2011. He told me in a phone conversation shortly after that witnessing the transformation in confidence and interpersonal social skills of residents was amazing. Some residents, he said, came into the group unable to piece together a sentence at first. Then after working together could eloquently testify at city council meetings. "It took a few years of hand holding," he said, but at some point residents stepped into community 

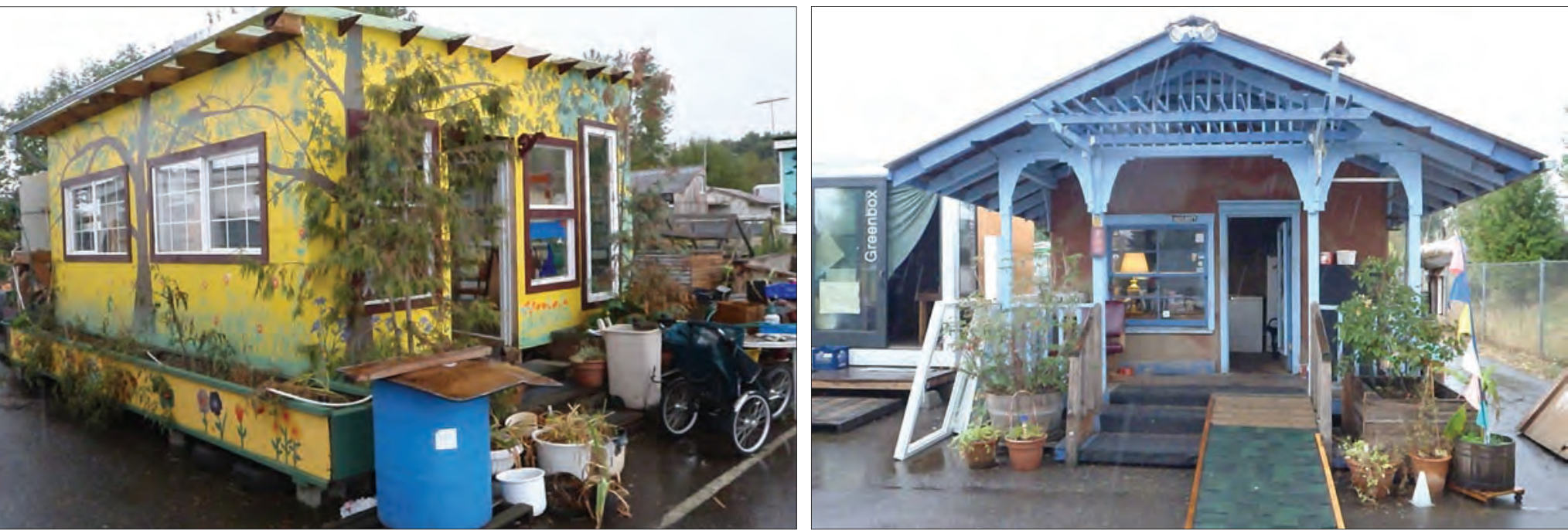

Figures 3 and 4: Example of stylish homes at Dignity Village. (photos by the author)

sufficiency (M. Lakeman, personal communication, 2011). (Because my visit was brief with only a few point-in-time conversations, I was not able to judge this claim.)

Homes

The 50 individual houses sat two to four deep along a road in a $\mathrm{T}$ off the main entry. Two-thirds were single occupancy and one-third were shared homes, David estimated. Propane heater boxes and tanks showed on exterior walls. Except for some homes with individual solar panels, there was no plumbing or electricity inside homes. Most structures were standard stick frame, ranging from trendy homemade Tiny House charm to tarp-tacked-over-roof-ramshackle. Accommodating for heavy rain events and rodent control, all residences were on platforms raised several feet off the ground.

As with a city block in a funky, gentrifying neighborhood, some structures in DV seemed to succeed and serve purpose. A vacant, half demolished straw bale and cob (sand, clay, and straw) structure stood decomposing in the weather, uninhabited by humans, an example of something that did not work.

"Rats," our guide David explained. Anyone who's experimented with natural home building materials probably has a few rodent stories. It is not altogether uncommon to confuse hay and straw, for example, an important distinction when binding earthen building mixes and doing straw bale construction. We seem to like to experiment with architectural form on our unhoused. They make for a ready concrete "problem" to "solve," and practically, without a lot of options, they make willing experimental subjects.

\section{Village Location and Transit}

Loud neighbors behind bars make for minimal opposition, but also mean DV residents have to travel some distance for services, such as food, healthcare and social services. Six miles from downtown Portland, it may take over 30 minutes by bicycle or by local bus to get from DV to other places. Residents probably benefit little from proximity to air travel, but bus Route 70 goes by the front entrance and connects to Bus 17. It takes about 45 minutes to get downtown to the social services center. When we visit, the cost of a day bus pass ranges from $\$ 2$ to $\$ 5$. Transportation costs can be a large part of Village residents' budgets. There were a couple of car parking spaces at the front of the Village, and David told us a few residents had cars. It is likely that residents often shared rides in an informal system of car sharing and reciprocity.

\section{Members and Rules}

Membership and residence in DV was of variable terms, contingent upon adherence to rules and a one-month trial residence period. In addition to pitching in for costs, DV residents, "members," were required to volunteer ten hours per week of community service and to follow a few rules: no violence, no theft, no constant disruptive behavior, and no alcohol or illegal drugs on-site or within a one block radius.

My experience living with a variety of persons in a variety of homes and communities-from "the fringes" in squatters' camps, Detroit, and mobile home parks to affluent and downscale traditional housing and with college freshmen in dormitories-is that the no alcohol and other even basic rules often prove problematic; some cannot and some will not follow rules. Paradoxically, persons living on the edge-those most in need of social assistance-are often those least able to follow rules and receive necessary social support (help from government, family, or their peers).

Social assistance requires some degree of playing by rules. College freshmen had to successfully play some game to get into college; they had to get decent grades, score high 
on the SAT, fence well, or write a brilliant essay to earn that acceptance letter. They showed they could follow rules of some sort. Still, they are infamous for causing trouble. Many probably choose to break rules. Others with poor social or organizational skills and those who suffer scars from trauma and abuse cannot follow rules for a variety of reasons. Society revokes offers of support as need becomes overwhelming and rules are not followed. And so we witness a messy conundrum of need and desire to support but inability to match the two. In the resulting gray zone, we are often not clear on who opts out and who is forced out. Blame escalates problems without solving them. While the housed ask why they, the unhoused, can't get their acts together, the unhoused ask why they, the housed, can't get their acts together.

Rules and blame thus become intricately wrapped up with the unhoused and housing issues, inside and outside of DV. Things get a little murky in the entangled mess. Officially, those who cannot or will not follow rules cannot be part of DV, just as troublesome freshman may get kicked out of the college dorm. The uncooperative college student may be able to rent a less well-regulated, noisy, dilapidated, party room off campus, but it is less clear where the former DV resident is supposed to go. In this way, many are excluded from service provision, in general. We want to accept people in various states of imperfection and allow for some hint of wild, but we do not want to enable people to be drunken idiots repeatedly peeing in the public realm. This leaves us all-housed and unhoused alike-caught in the messy bind.

\section{Resident composition}

David, our guide, told us that males over 30 comprised twothirds of DV residents, and one-third of residents were women. "Any single woman is not single for long," he added with a smile. There are possible advantages to being a minority, in addition to challenges. (A discussion of gender dynamics here would be fascinating, as in most communities, but is outside the scope of this brief study.) As resident members move out, new residents are accepted after a temporary member trial period. Compatibility is tested with gradual moves from common house sofa to dorm room to individual house and community membership.

Originally, there was a limit on the time people were allowed to stay in homes; DV was considered transitional housing. Exceptions have often been made, David explained, because of such few other housing options to move on to. Some residents, he said, have made DV home for several years. At the time of our tour there was a waiting list of ten or twelve persons, David said.

\section{Benefits}

DV met a variety of lofty higher-level and lower-level practical objectives as a middle-ground alternative to "institutional warehousing" (shelters) or "doing nothing" (sleeping by the creek or on the sidewalk). DV provides both benefit to residents

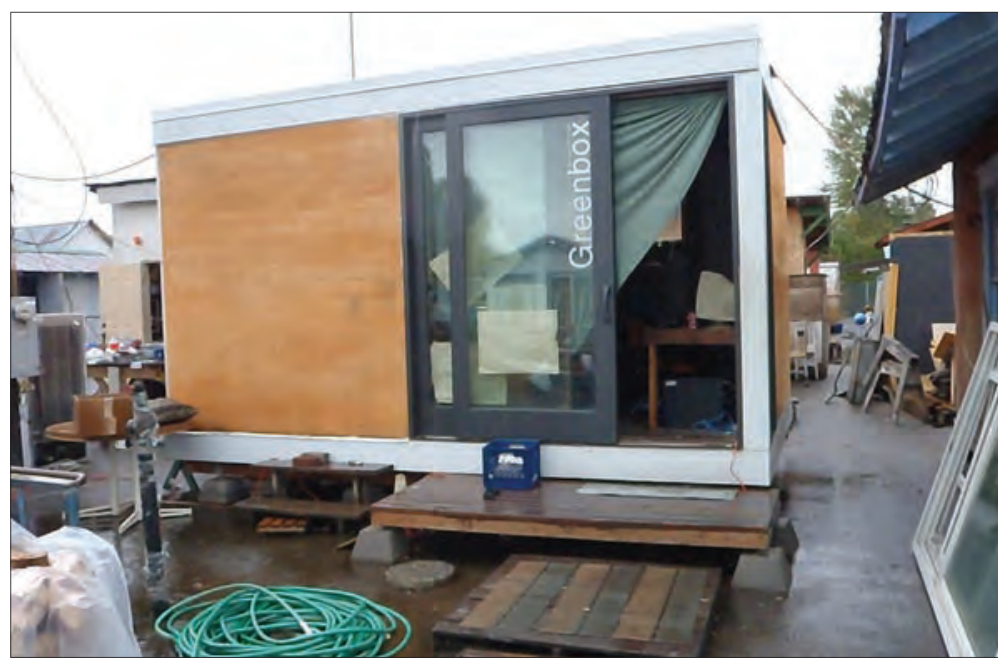

Figure 5: A modernistic house. (photo by the author)

Figure 6: A sign with Dignity Village's Basic Rules: part of the community selfgovernment.

(from http://en.wikipedia. org/wiki/File:Dignity_Village_ Rules.jpg\#mediaviewer/

File:Dignity_Village_Rules.jpg)

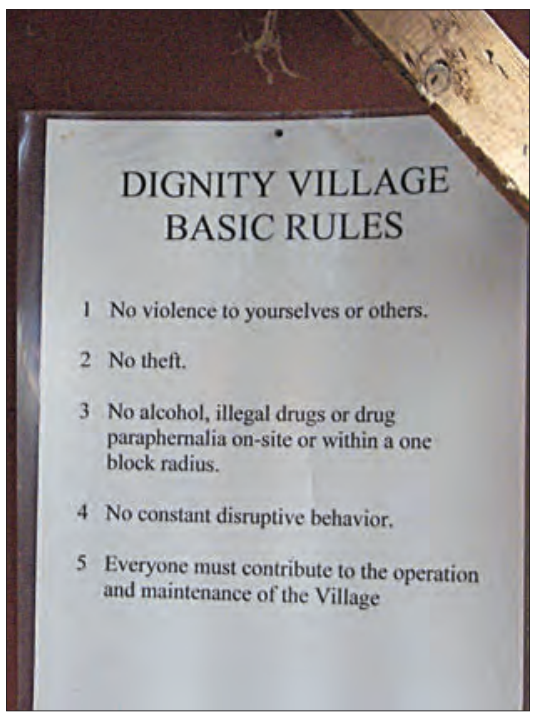

Figure 7: Community control; the sign asks visitors to check in and out. (photo by the author)

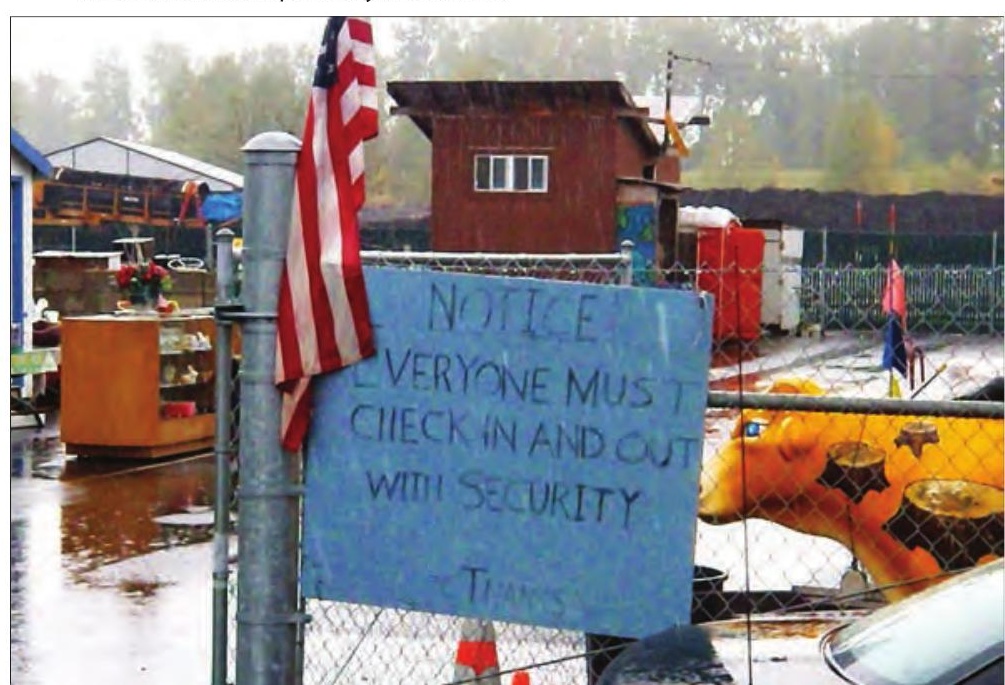


and benefit to the greater community of non-residents. Although de facto subsidized with city land, DV falls outside of typical government "by-the-book help" response. This creates benefits and challenges, and is a point of contention, primarily as relating to funding, creative application of codes, and oversight costs to the City. DV resident members' accountability for following rules and instituting basic safety measures, such as fire prevention requirements, is essential.

Resident benefits:

- Middle ground housing: Safe, adequate protection for persons and possessions from predation and elements; between permanent standard housing and tents by the creek; provides cross between "permanent" and "temporary" shelter; a foothold.

- Dignified existence: Ability to live and work without constant fear and requirement to keep moving around.

- Self-sufficiency/Autonomy/Self-governing: Self-operated construction, management, security, fundraising; people create and maintain their own space.

- Second chance: Allows those penalized and locked out of opportunity because of previous transgressions/ convictions.

- Pets allowed: Often not allowed in other shelter for the unhoused.

- Couples allowed to room together: Often not allowed in other shelter for the unhoused.

- Continuity: No daytime lock out/constant disruption, moving between daytime and nighttime facilities, lines, uncertainty, and constantly different rooms and beds, as at many facilities.

- Low cost: Monthly housing fees as low as $\$ 50$ per month (calculations below).

Community Benefits:

- Cleaning and greening public spaces: By providing a place for the unhoused and keeping it safe and tidy, other places can be less impacted; trash and refuse will be adequately placed rather than dumped into parks, public areas, and creeks.

- Environmentally sound: Small, simple self-built structures in a compact "community" use less resource than other types of housing; an autonomous organized community can find appropriate environmentally conscious ways to dispose of sewage and trash, and minimize environmental impacts of residence.

- Efficient: With donated time and materials, the average cost of DV houses was $\$ 200$ each to build. With total operational expense of approximately $\$ 3,000$ per month, the cost per person of community living at DV is about $\$ 50 /$ person/month. One month of housing expense for all DV equals about the cost of two average families' monthly expenses, or for each person, the equivalent of a dorm bed in a hostel for two nights, or about one-third the cost of warming centers (Frost, 2011). Most of the operational cost was for utilities: fuel charges (cooking and heat); porta-potty dumping; electricity to common house; and trash collection. Firewood sales, Ebay, and nursery sales contributed some income to the group to offset operational costs.

- Reduction of public costs of services. Public service dependence, such as for police, emergency room, and jail, decreases as unhoused persons get into comfortable, safe, dignified housing. In one study, costs of emergency room visits alone decreased from over $\$ 28,000 /$ year to just over $\$ 6,000 /$ year per person when unhoused persons were provided with homes.

- Community empowering: The Village project gives housed community members a place to contribute hands on and to learn about the needs of the unhoused and benefit from their skills and resourcefulness, and a place for the unhoused to work together and interact. Community members, frustrated by the failures in our system, seek constructive ways to help their neighbors. The Village model offers constructive forms of interactive participatory collaboration, which helps both housed and unhoused populations.

\section{Challenges and Lessons}

One San Luis Obispo advocate for the unhoused told me recently he fears appearing "a nut." He says his middle class friends do not want to hear about "homeless and homelessness issues." I share a similar experience: when I first met this guy I wondered if he was a nut too. Similarly, when I moved into a squatters camp called Slab City for a couple of winters to study issues of alternative housing, housing prejudice, off grid living, and then carried my study on to Metro Detroit, residential hotels, mobile home parks and sleeping on the

\section{Figure 8: Dignity Village's community garden. (photo by the author)}

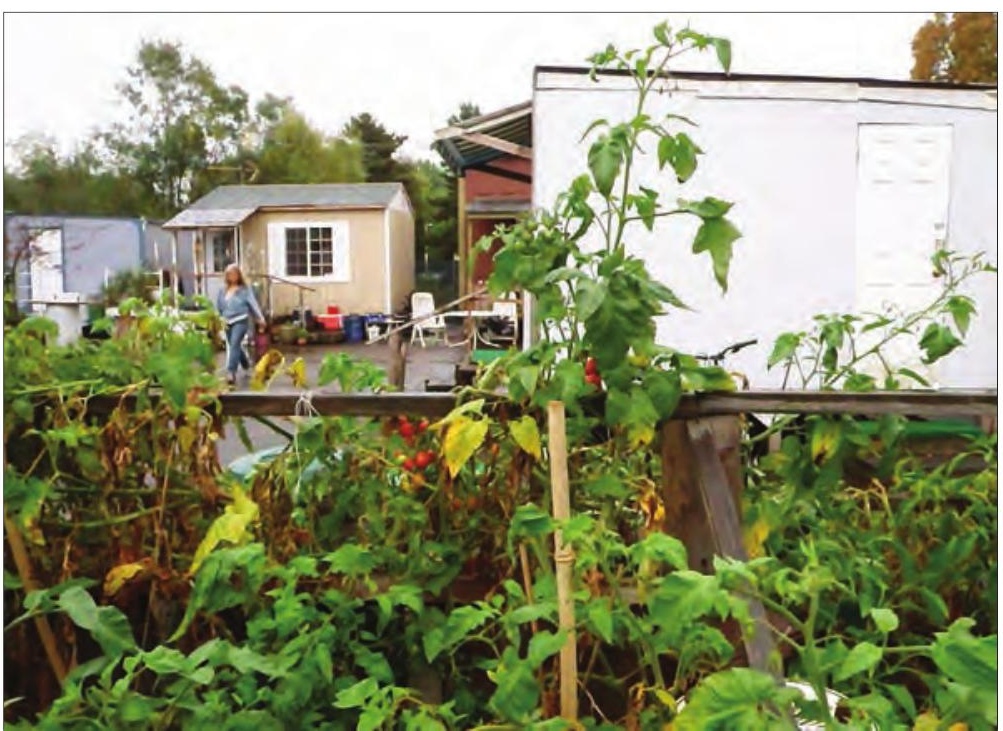


side of the road, there was some general suspicion that some of my own marbles went missing. More troubling, I shared these questions about myself. It is important to watch how we judge and get judged for experimenting with housing and community deemed outside societal norms, acknowledging challenges and human potential and calling attention to issues some others have chosen to ignore.

Given this setting, DV creation and operation has been and remains fraught with challenges, as with other such housing around the country. In a study of American tent cities, Heben (2011), who briefly lived in Ann Arbor, Michigan's Camp Take Notice, counts approximately two-dozen sanctioned and unsanctioned and organized or unorganized "tent villages" across the country. Sanctioned, organized villages, such as DV, have approvals to use the land they occupy and some system of group organization. Unsanctioned, unorganized villages, on the other hand, such as Slab City, where I have spent several months, have no approval for the ground they occupy and no group system of governance. Although order and reciprocity is the norm, in my limited experience, these villages have no formal systems of organization.

\section{General challenges include:}

- Prejudice/Classism: Society often frowns upon those living lightly; there are "visible" and "invisible" unhoused: often visible unhoused are more unpalatable than invisible unhoused who, embarrassed about their situations, quietly hide.

- Fear and criminalization of unhoused: Trespassing and sleeping on sidewalk charges are common against nonviolent unhoused persons.

- Causal confusion: Unhousedness is often a result of trauma. There is a societal failure and lack of understanding of persons facing trauma, including: veterans, penal inmates, and sufferers of child abuse and molestation.

- Needs: These extend beyond housing to need for understanding, healthcare and community; access to these resources involves time, money, and distance.

- Many now denied access to services: Sexual offenders (California 290s and 288s), persons with no ID, mentally ill, and others land in this category. Many of these residents with unmet needs are desperate for housing but are difficult to serve, with limitations on places they can legally be, mental challenges, and other parole reporting requirements. While it is necessary to protect citizens and limit repeat offenses, it is not clear what options many of these persons have.

- Finance/Equity vs. Efficiency/Allocation of limited resource: Conflicts arise over who to serve and who gets what. When a village is considered "temporary" (often by necessity for approvals), there is resistance to paying infrastructure costs for a "temporary" village. DV residents and residents in San Luis Obispo alike express unhappiness at the public expense for some unhoused services. [Just prior to our Village tour, Portland opened the Bud Clark Commons, housing and services for the unhoused, at a cost of approximately $\$ 50$ million. It has 130 apartments for formerly unhoused persons, a 90 bed men's shelter, and day use facilities.] DV residents were angry they did not get help with their \$50 per month expense once they knew that the new Clark Commons residential unit occupants received a much larger subsidy.

- Aesthetic/Standard of beauty: As with other such camps, Dignity Village was not beautiful. The day we visited, the entry could be described as artsy or looking like a swap meet, with various items spread out on tables for sale. (A messy example of why we zone business out of residential areas while we talk about encouraging community selfsufficiency and mixes of uses.) Signs of disrepair were evident amongst accumulating "stuff." The lives of persons on the edge are not tidy with purple Target storage bins and garages to conceal accumulations.

"Government agencies can't keep drugs and alcohol out of federal prisons. It is a consistent problem here." -David

Organizational and operational challenges include:

Governments are charged with providing some basic level of safety and security for citizens. This means either they are obligated to provide it, in some fashion, or they turn a blind eye to operations, by necessity. Because DV is on land owned by the City of Portland, the blind eye is out of the question. There is need to provide strong organizational support, training, and guidance to ensure that promises for safety and orderly conduct to grantors of land, services, and other code exempting agents and agencies will be kept. Maintaining an engaged community of residents and volunteers to ensure enforcement of rules and fair application are ongoing challenges, as with any group of people anywhere. Other challenges include:

- Terminology and tenure confusion: As things stand, when we talk about DV residents today, there remains confusion whether we are talking about "housed" persons or "unhoused" ones. The same questions are asked about the village itself: is it temporary or a permanent facility, a village or a temporary warehouse? Different answers affect investment in camp infrastructure and attitude of residents and others toward residents: If the village is perceived as long term, more investment in infrastructure may be prudent. If short term, less infrastructure and more fast tracking to get people a step up from under bridges may be useful.

- Cliques and favoritism: As with any group, cliques form in DV and favoritism affects rule enforcement and distribution of group costs and benefits between individual members. 
- Partnering and rule following: Special needs groups, such as the unhoused served by DV, are the most in need of solid partnerships and partnering, but ironically, are often the type of group and individuals inherently least able to forge partnerships, due to fears and lack of trust resulting from historical trauma, lack of social skills, and inability or unwillingness to follow rules.

- Physical site: Finding adequate, appropriate and available site for villages is challenging. Village location should be close to city services and job centers but also must be a place with few neighbors to disrupt with visual messiness, noise, smoke, and other impacts.

- Health and safety: Village concept can be safe but often requires flexible, creative application of codes, including fire, building, planning, and health.

\section{Takeaways: Lessons from Portland}

- Build community facilities first: In a self-build model, such as DV, it gets harder to focus on community infrastructure if individual homes are constructed first. At DV, individual homes were constructed prior to the construction of the common house. As individual homes were finished, work on community facilities lagged. Construction of community infrastructure prior to home construction would have minimized such challenge (M. Lakeman, personal communication, 2011).

- Consider distinctions between permanent and temporary: "Campground," "Village" or "Tiny house Village" would work better than the more common terms "homeless encampment" or "tent city." Tenure of both Village and its residents should be considered upfront. Should Village and residents be permanent or temporary? Costs and benefits of permanent and temporary: does moving encourage people to move on and upward? Does moving Village itself around require more neighborhoods to share in impacts and benefits from camp? (Heben, 2011).

- Minimize car parking spaces and other storage spaces: "Things will accumulate if space is provided," (M. Lakeman, personal communication, 2011). "Provide space for people and limited space for stuff."

- Use structures to create edges for common areas: Look at blank space as positive space in terms of public/shared use/outdoor areas (M. Lakeman, personal communication, 2011).

- Build communication skills: Many, even the most unskilled in community building and management techniques, can become highly skilled with appropriate training and assistance (M. Lakeman, personal communication, 2011).

- Understand target population: Set priorities for who will be served and not served upfront: Will Village serve felons and/or sexual offenders, adults or families, people who expect to drink alcohol; understand and use triage model which assesses needs to put people in right places; understand that many homeless persons choose to live alone or are incapable or unwilling to work with a group or follow rules and respect that choice; provide communication training and outreach, but do not expect it will be universally accepted.

- Maintain partnerships: In addition to resident oversight and communal governing body, provide outside group or responsible party to guarantee that promises to partners are being met, e.g., health and safety requirements and member rules enforced.

- Alternative housing type issues and architectural experimentation: Some experiments fail; proceed with caution.

\section{Conclusion}

Seeds sprout from molten lava, despite their odds. Challenges and messiness do not keep seeds-in the form of good ideas or hope-from taking root. Sometimes beauty comes outside our rigid societal standard of "decent" aesthetic. Dignity Village provides a practical model that can be an efficient middle-ground on which we can shelter and empower a segment of our current unhoused population, even those most challenging to serve. It is another useful tool to help us build stronger community and provide shelter for our neighbors.

My experience living in several unconventional, tiny dwellings, such as these, is that in decent weather, with adequate windows and light, many forms of dwelling can be both safe and pleasant, even if frowned upon societally and "substandard," according to government code. Small size and simplicity of structures can make them easy to clean and maintain, open time for activities other than housekeeping and maintenance, and allow income to go toward more than just housing. Beyond this, sense of community derived from common facilities and shared experience there can be an asset to some, as opposed to detriment. (Think bonding at summer camp in a dorm room.) The safe, simple residences and transformed lives at Dignity Village reflect this experience.

Because individual unconventional homes often have limited or no infrastructure, such as water, sewer, and power, provision of common amenities, clean water and adequate methods for dealing with wastes, are essential. It is important for the health, safety, and wellbeing of residents of any proposed community that a certain amount of community infrastructure and services be provided, even if not available in every housing unit. Dignity Village, a small seed struggling to break through the lava, illustrates that basic living in community can work for some and has the power to transform lives. Both the housed and unhoused can benefit. 


\section{More Information and References}

Dignity Village. Retrieved from http://www.dignityvillage.org/. 9401 N.E. Sunderland Ave, Portland, OR 97211.

Dignity Village Council with others. (2003). Dignity Village Proposal, 2004. Retrieved from http://dignity.scribble. com/ proposal2003/

Heben, A. (2011). Inside tent cities. Planning, 77(8), 23-25.

Hope's Village of San Luis Obispo. Retrieved from: http:// hopesvillageofslo.com/

Lakeman, M. et al. (2004). Dignity Village Vision Plan.

Frost, A. (Contributor). (2011, June 15). Dignity Village and Ending Homelessness [Audio podcast]. Retrieved from Oregon Public Broadcasting Think Out Loud website: http:// www.opb.org/thinkoutloud/shows/dignity-village-andending-homelessness/

SLO County housing the unhoused. See Path to a Home: San Luis Obispo Countywide 10-Year Plan to End Homelessness at: http://www.slocounty.ca.gov/Assets/PL/Housing/10+Year +Plan+to+End+Chronic+Homeless+Plan.pdf 